\title{
Take-the-best in expert-novice decision strategies for residential burglary
}

\author{
Rocio Garcia-Retamero \\ University of Granada, Granada, Spain \\ AND \\ Mandeep K. DHAMI \\ University of Cambridge, Cambridge, England
}

\begin{abstract}
We examined the decision strategies and cue use of experts and novices in a consequential domain: crime. Three participant groups decided which of two residential properties was more likely to be burgled, on the basis of eight cues such as location of the property. The two expert groups were experienced burglars and police officers, and the novice group was composed of graduate students. We found that experts' choices were best predicted by a lexicographic heuristic strategy called take-the-best that implies noncompensatory information processing, whereas novices' choices were best predicted by a weighted additive linear strategy that implies compensatory processing. The two expert groups, however, differed in the cues they considered important in making their choices, and the police officers were actually more similar to novices in this regard. These findings extend the literature on judgment, decision making, and expertise, and have implications for criminal justice policy.
\end{abstract}

Choices can be made using different cognitive strategies. For instance, imagine deciding which of two residential properties is more likely to be burgled. The properties may be described in terms of several cues, such as whether they have a full mailbox or the lights are switched off. One strategy that can be employed is a weighted additive linear model (WADD). For each property, WADD computes the sum of all cue values multiplied by the cue weights, and selects the property with the largest sum. An alternative, simpler strategy is take-the-best (TTB; Gigerenzer \& Goldstein, 1996). TTB selects the property ranked highest in terms of its cue weight if the cue value discriminates between the two properties (e.g., one property has a full mailbox but the other does not, given that the mailbox cue is ranked first). If the first ranked cue does not discriminate, the second ranked cue is considered, and so on. If no cue discriminates between the alternatives, TTB selects randomly. WADD involves compensatory processing of cue information, whereas TTB involves noncompensatory processing. Both strategies have been commonly used as prototypical examples of these two types of processes.

Research on predicting environmental criteria, where TTB and WADD use cues according to their predictive validities, has demonstrated that TTB can make more accurate choices than WADD in several domains, including economics, but has not examined the crime domain (Czerlinski, Gigerenzer, \& Goldstein, 1999). Studies of behavior have similarly shown that peoples' choices are better predicted by TTB than by WADD (Bergert \& Nosofsky, 2007), especially under high information ac- quisition costs (e.g., Bröder \& Gaissmaier, 2007; GarciaRetamero, Hoffrage, \& Dieckmann, 2007) or time pressure (Rieskamp \& Hoffrage, 2008). However, this research has typically involved participants making decisions in artificially constructed tasks that are unfamiliar and irrelevant to them. It is also unknown whether people use such heuristics in the crime domain.

Studying participants under unrepresentative conditions may distort their typical behavior, leading to findings lacking in external validity (Dhami, Hertwig, \& Hoffrage, 2004). Participants may appear less competent when their previous knowledge and experience are stripped away (Garcia-Retamero, Wallin, \& Dieckmann, 2007). The few studies of simple heuristics that have examined participants with prior task experience, such as magistrates and physicians, have shown that these professionals' behavior is better predicted by a heuristic strategy than by WADD (Dhami \& Ayton, 2001; Dhami \& Harries, 2001). However, these studies did not distinguish between the strategies employed by more and less experienced professionals.

Evidence reveals that experts and novices differ in their decision making (Shanteau, 1992a, 1992b). For instance, experts use less, but more relevant, information than do novices (e.g., Shanteau, Grier, Johnson, \& Berner, 1991), who are influenced by irrelevant information. Experts appear to rely on implicit, automatic, and fast processes, whereas novices rely on explicit, controlled, and slower processes (e.g., Shanteau, 1988). Experts may employ noncompensatory strategies, whereas novices may rely on more cognitively complex strategies (Johnson \& Payne, 
1986; although there are claims that clinicians use nonlinear strategies). Cognitive continuum theory (see Hammond, 2000) proposes that familiar tasks are more likely to induce intuitive processing, which has been associated with use of heuristics (Gigerenzer, 2007). To date, no one has examined the decision strategies of experts and novices in terms of whether they are more likely to employ heuristics such as TTB or more complex strategies such as WADD. Furthermore, no one has compared the strategies of experts who approach a task from different perspectives. They may be similar in their strategy (e.g., employing heuristics) but different in their cue use (i.e., relying on different cues), or vice versa. Indeed, one expert's perspective may be closer to that of a novice than to another expert's.

These questions are pertinent where crime is concerned. Novices (citizens) and expert police officers must predict the behavior of expert offenders. In residential burglary, for example, researchers have found that experienced burglars exhibit characteristics associated with expertise (e.g., Wright, Logie, \& Decker, 1995). Burglars are more likely than residents to distinguish between cues that are incentives or deterrents for burglary (Nee \& Taylor, 2000). Recently, Nee and Meenaghan (2006) found that burglars use sequential search, focus on relevant cues, and employ automatic and speedy strategies. Furthermore, experienced burglars differ from nonoffenders or residents and police officers in the cues they use to select targets (e.g., Shaw \& Gifford, 1994; Wright et al., 1995). However, it is unknown whether burglars differ from police officers and residents in the decision strategy they employ (rather than in the cues they use).

We examined the strategies and cue use of experts with different perspectives (i.e., experienced burglars and police officers) and novices (i.e., graduate students) when predicting residential burglary. Are experts' choices more likely to be predicted by TTB and novices' choices more likely to be predicted by WADD? Is one expert perspective more similar to novices' in terms of cue use? How is the degree of expertise related to strategy? Answers to these questions have implications for theories of decision making and expertise, as well as for criminal justice policy and practice.

\section{METHOD}

\section{Participants}

One hundred twenty individuals volunteered to participate in the study, without financial incentive. They formed three equally sized groups: burglars, police officers, and graduate students. Forty burglars were recruited from one English prison for men. Their mean age was 33.20 years $(S D=6.26)$, and the majority $(69.23 \%)$ had at most a secondary school education (i.e., up to age 16). Burglars had reportedly committed burglary on an average of 57.18 occasions $(S D=39.82)$. Forty police officers were recruited from a professional graduate program at a British university. They were mostly male (33), with a mean age of 41.28 years $(S D=6.03)$; the majority $(82.50 \%)$ had a university education. Police officers had worked for an average of 19.39 years $(S D=6.63)$ and had investigated residential burglaries. Finally, 40 students were recruited from the regular graduate program at the same university. Thirteen were male; the sample had a mean age of 26.13 years $(S D=5.97)$. Students reported being a victim of burglary on an average of 0.58 occasions $(S D=1.01)$.

It was not possible to control for demographic variables such as age, gender, and education. The three groups were significantly different in terms of mean age ( $p<.001$ for all comparisons), the novice group differed significantly from the expert groups in terms of gender ( $p<.001$ for both comparisons), and the burglar group differed from the police and student groups in terms of education ( $p<.001$ for both comparisons). As mentioned below, these differences did not affect the results.

\section{Design and Stimuli}

Participants completed a three-part survey that allowed comparison of experts and novices in terms of the cues they considered to be important for choosing which of a pair of residential properties was more likely to be burgled, and in terms of the strategy that best predicted their choices in such a task. The study focused on deci-

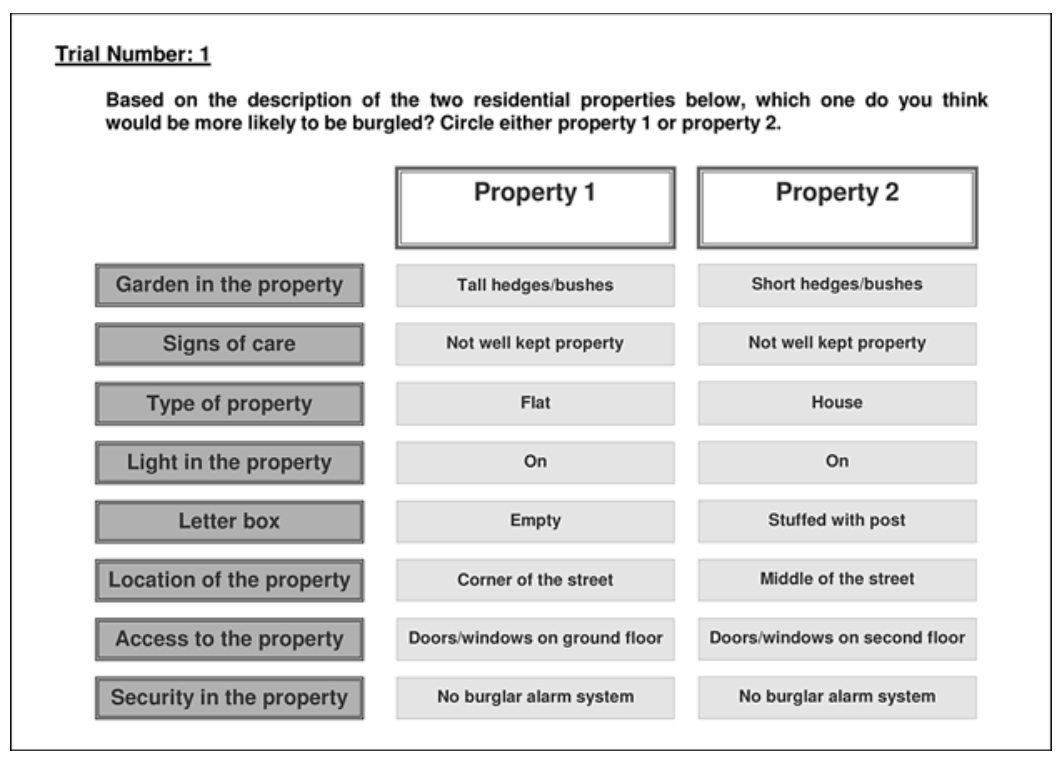

Figure 1. Screenshot depicting the task. 
Table 1

Positive and Negative Values for the Eight Cues

\begin{tabular}{lll}
\hline \multicolumn{1}{c}{ Cue } & \multicolumn{1}{c}{ Positive Value } & \multicolumn{1}{c}{ Negative Value } \\
\hline Garden in the property & Tall hedges/bushes & Short hedges/bushes \\
Signs of care & Not well-kept property & Well-kept property \\
Type of property & Flat & House \\
Light in the property & Off & On \\
Letterbox & Stuffed with post & Empty \\
Location of the property & Corner of the street & Middle of the street \\
Access to the property & Doors/windows on ground floor & Doors/windows on second floor \\
Security in the property & No burglar alarm system & Burglar alarm system \\
\hline
\end{tabular}

sion making with already acquired strategies. Issues of information search and choice accuracy were not within the scope of the study.

In the first part of the survey, participants were provided with information, such as whether there was a burglar alarm system (see Figure 1), on eight cues describing each of 40 pairs of properties. These cues were selected after a review of the literature on residential burglary (e.g., Buck, Hakim, \& Rengert, 1993; Ham-Rowbottom, Gifford, \& Shaw, 1999; Shaw \& Gifford, 1994). The cue values for both properties were coded as either positive or negative, and, according to the literature, positive values put the property at greater risk of burglary (see Table 1). For each pair, participants chose which property was more likely to be burgled.

The 40 pairs of properties were created to test which strategy, TTB or WADD, better predicted participants' choices (see Rieskamp \& Otto, 2006, for a similar procedure). Cue values for each property were generated randomly under the following constraints: For each cue, half the properties had a positive value and half a negative value. Therefore, the discrimination rate (i.e., the number of paired comparisons in which cue values differed between properties) of all the cues was $50 \%$. The intercorrelations among the cues were from -.10 to .10. At least one cue discriminated between each pair of properties. Therefore, for each paired comparison, the strategies made unambiguous predictions, and participants made unambiguous choices.

In the second part of the survey, participants ranked the cues according to how useful they would be in predicting the likelihood of a property's being burgled, where the first rank was assigned to the most useful cue. Finally, in the third part, participants estimated the weight of each cue (see Garcia-Retamero, Takezawa, \& Gigerenzer, 2008). For instance, for the security in the property cue, they were asked,
Imagine two residential properties. One of the properties has no burglar alarm system. The other has a burglar alarm system. In how many cases like this would the property with no burglar alarm system be more likely to be burgled than the property with a burglar alarm system?

Participants responded on scales from 50 to 100 , marked with 10 -point intervals.

\section{Procedure}

The paper-and-pencil survey was individually self-administered. Participants also provided their own demographic details. There were no time constraints, but the survey took approximately $45 \mathrm{~min}$ to complete. The order of the 40 pairs of properties was randomized across participants. The order of cues was fixed for each participant but varied randomly across participants.

\section{RESULTS}

\section{Do Experts Differ From}

\section{Novices in Their Cue Weights?}

A mixed ANOVA with participants' cue weight estimations as the dependent variable, and group and cue as between- and within-subjects factors, respectively, was computed. There was only a significant main effect of group $[F(5.55,655.01)=21.99, p<.01]$, and a significant group $\times$ cue interaction effect $[F(11.11,655.01)=$ $3.63, p<.01]$. As can be seen in Figure 2, police officers' mean cue weight estimations were similar to those of

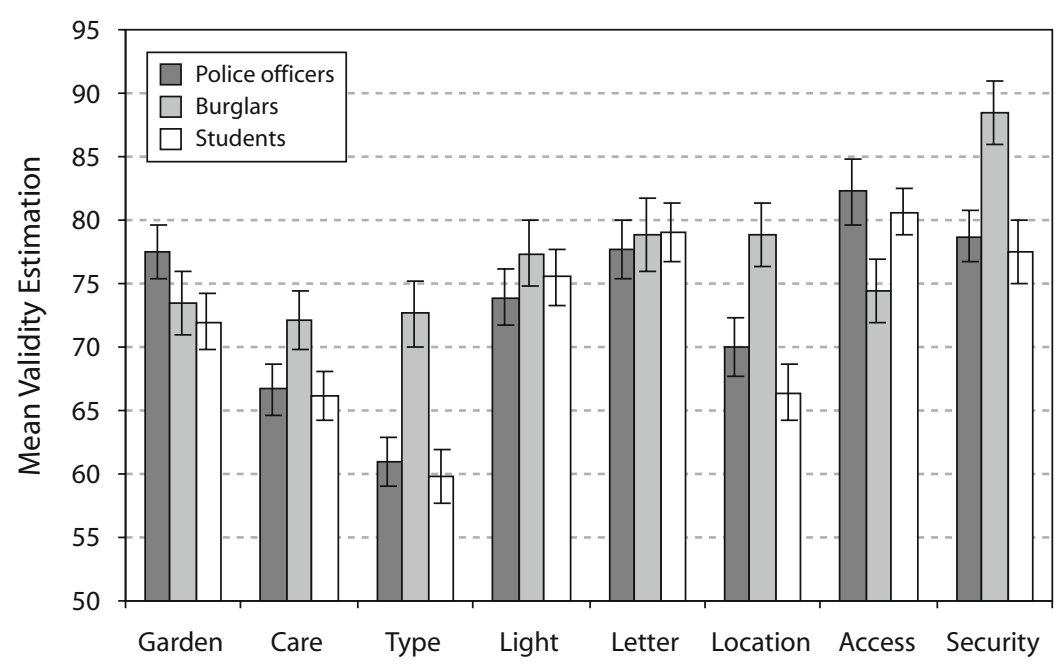

Figure 2. Police officers', burglars', and students' cue weight estimations. Error bars represent one standard error. 


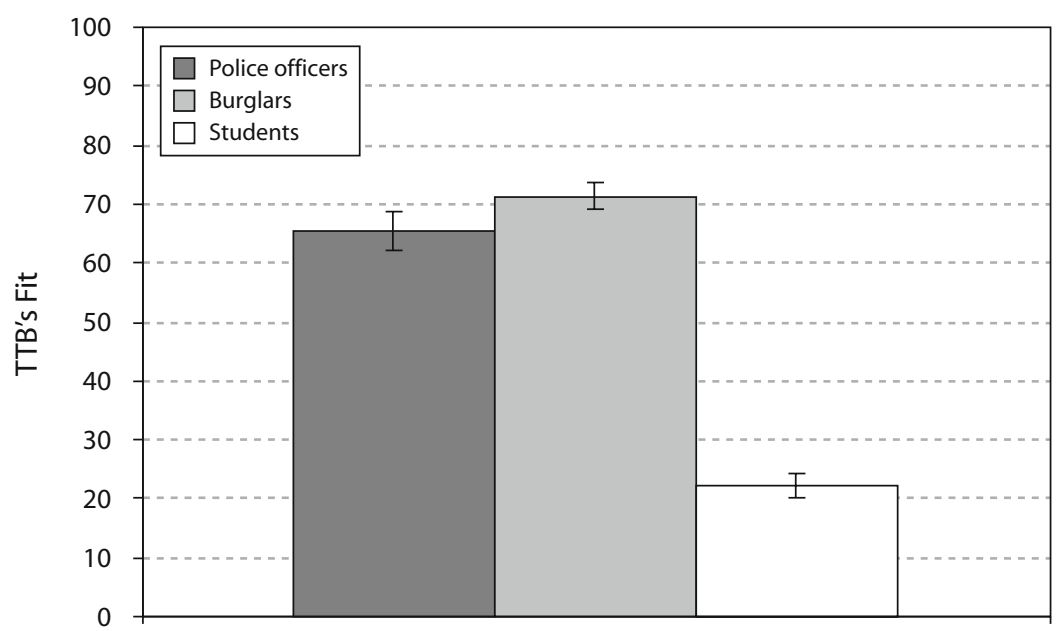

Figure 3. Percentage of choices predicted by TTB for police officers, burglars, and students in the discriminating trials where TTB and WADD made opposite predictions. Predictions for the two strategies sum up to $100 \%$; a low fit for TTB implies a high fit for WADD and vice versa. Error bars represent one standard error.

students, but significantly different from those of burglars ( $p<.05$ for both comparisons, using Tukey's HSD test). Burglars' mean cue weight estimations for security in the property, location of the property, and type of property were significantly higher than those of police officers and students. In contrast, police officers' and students' mean cue weight estimations for access to the property were significantly greater than those of burglars $(p<.05$ for all comparisons).

\section{Do Experts Differ From Novices in the Decision Strategies That Predict Their Choices?}

Participants' cue weight estimations were used as the cue weights for WADD and to imply cue rankings for TTB (see, e.g., Garcia-Retamero et al., 2008). ${ }^{1}$ For each participant, the predictions of TTB and WADD were compared with his/her choices, and the percentage of choices predicted correctly by each strategy was computed (i.e., strategy fit). ${ }^{2}$

We computed the fit of TTB and WADD over all 40 paired comparisons by determining the proportion of participants' choices accurately predicted by each strategy. The percentage fits for WADD and TTB were $63.00 \%$ and $71.66 \%$, respectively, for burglars $[t(39)=-8.25, p<$ $.001]$; $66.98 \%$ and $73.65 \%$, respectively, for police officers $[t(39)=-4.47, p<.001]$; and $77.00 \%$ and $65.05 \%$, respectively, for students $[t(39)=11.45, p<.001]$. Thus, experts' choices are more likely to be predicted by TTB, and novices' choices are more likely to be predicted by WADD.

We further analyzed the fit of the two strategies on the paired comparisons in which the strategies made opposite predictions (i.e., discriminating trials; see, e.g., Rieskamp $\&$ Otto, 2006). ${ }^{3}$ A mixed ANOVA was computed on these trials with participants' choices as the dependent variable. ${ }^{4}$ Group and strategy were the between- and within-subjects factors, respectively. There was only a significant group $\times$ strategy interaction effect $[F(2,117)=100.64, p<.001]$ (see Figure 3). Using Tukey's HSD test for post hoc comparisons, we found that WADD had a significantly higher fit for students than TTB did, with an average of $77.94 \%$ correct predictions as opposed to $22.06 \%$, respectively $(p \mathrm{~s}<.01)$. By contrast, TTB had a significantly greater fit on average for burglars and police officers than WADD did, with TTB correctly predicting $71.39 \%$ and $65.36 \%$ of burglars' and police officers' choices, respectively, as opposed to WADD's $28.61 \%$ and $34.64 \%$, respectively ( $p$ s $<.01)$.

To further explore the strategies that best predicted participants' choices on the discriminating trials, we classified participants as using either TTB or WADD, according to the strategy that achieved the highest fit, if the fit of the two strategies differed by at least $10 \%$. This was based on the distribution of the fitting scores (see Mata, Schooler, $\&$ Rieskamp, 2007). Those participants $(n=5)$ for whom the fit of the two strategies coincided or differed by less than $10 \%$ were unclassified. As Table 2 shows, most police officers' and burglars' choices were classified as being better fit by TTB than by WADD $\left[\chi^{2}(1)=39.00, p<.001\right.$, for police officers, and $\chi^{2}(1)=37.00, p<.001$, for burglars]. In contrast, most students' choices were better fit by WADD than by TTB $\left[\chi^{2}(1)=39.00, p<.001\right]$.

Finally, as mentioned earlier, the three groups differed in ways other than expertise (i.e., in terms of age, gender,

Table 2

Strategy Classification by Group

\begin{tabular}{|c|c|c|c|c|c|c|}
\hline & \multicolumn{2}{|c|}{$\begin{array}{c}\text { Police } \\
\text { Officers }\end{array}$} & \multicolumn{2}{|c|}{ Burglars } & \multicolumn{2}{|c|}{ Students } \\
\hline & $N$ & $\%$ & $N$ & $\%$ & $N$ & $\%$ \\
\hline WADD & 8 & 20.00 & 3 & 7.50 & 38 & 95.00 \\
\hline TTB & 31 & 77.50 & 34 & 85.00 & 1 & 2.50 \\
\hline Unclassified & 1 & 2.50 & 3 & 7.50 & 1 & 2.50 \\
\hline
\end{tabular}

Note-TTB, take-the-best; WADD, weighted additive linear strategy. $N=40$ for all three groups. 
and education). Even though there is no previous research to suggest that these factors have an impact on strategy use, their potential confounding effects should be ruled out. Using strategy fit over the discriminating trials as the dependent variable, we found no significant main effect of gender or gender $\times$ strategy interaction for the police officer group or the student group ( $p$ s $>.05$ ); burglars were all male. Similarly, there was no significant main effect of education or education $\times$ strategy interaction for the police and burglar groups; the students were all similarly educated $(p \mathrm{~s}>.05)$. There were no significant correlations between age and strategy fit $(p s>.05)$. Finally, there were also no significant effects of these demographic variables on cue weights $(p s>.05)$.

\section{How Is Degree of Expertise \\ Related to Decision Strategy?}

We correlated the fit of TTB over the discriminating trials with the degree of expertise of participants in each group. ${ }^{5}$ Degree of expertise was measured in terms of the number of years the police officers had worked for the force, the number of occasions on which burglars reported having committed burglary, and the number of occasions on which students had reported being victims of burglary. The correlation was .36 for police officers, .37 for burglars $(p s=.05)$, and -.10 for students $(p>.50)$.

\section{DISCUSSION}

We examined the decision strategies that best predicted the choices made by two expert groups with different perspectives (i.e., experienced burglars and police officers) and one novice group (i.e., graduate students). Burglars' and police officers' choices of residential properties likely to be burgled were better predicted by TTB, a noncompensatory, lexicographic heuristic. By contrast, students' choices on the same task were better predicted by WADD, a compensatory strategy. This conclusion was consistent across analyses over all 40 paired comparisons, over only the discriminating trials, and via classification of participants to their best fit strategy using a stringent criterion (i.e., $10 \%$ point difference between fit of strategies). Moreover, this conclusion was not tempered by group differences in age, gender, and education. In fact, the fit of TTB was positively associated with degree of expertise within the burglar and police groups, but was not associated with expertise in the student group. These results support the idea that task familiarity and experience or training are more likely to result in use of heuristics because they induce intuition.

Although it could be argued that participants' choices might have been even better predicted by variants of TTB and WADD, it is unlikely that our main conclusionnamely, that experts' choices are better predicted by a noncompensatory strategy and novices' choices are better predicted by a compensatory strategy - would change. Johnson and Payne (1986) noted that, as people become more experienced in a task, they are more likely to employ noncompensatory strategies. In fact, the present findings are consistent with previous research showing that the decisions of experienced professionals are more likely to be predicted by simple heuristics than by WADD (Dhami \& Ayton, 2001; Dhami \& Harries, 2001), whereas naive participants' choices are better predicted by WADD than by TTB (Rieskamp \& Otto, 2006).

Experienced police officers may employ heuristics because, as Shanteau (1992a) argues, the task they facepredicting human behavior-is likely to stimulate intuitive rather than analytic processing (see also Hammond, 2000). According to Shanteau (1992a), predicting human behavior is a "poor-performance" task, since humans can be inconsistent; so it should not be surprising that police officers, like other experts such as court judges, are often inaccurate (e.g., they cannot predict which property a burglar may select). For burglars, on the other hand, using a heuristic such as TTB might be adaptive, since such a strategy requires little time, information, and cognitive capacity (Gigerenzer \& Goldstein, 1996). These are often the conditions under which crimes are committed, and strategies that are more resource intensive may be penalized. In naturalistic environments, there also tends to be some redundancy among cues, so that fewer cues are required to achieve inferential accuracy (e.g., Phelps \& Shanteau, 1978); under such conditions, heuristic strategies perform as well as do strategies that integrate all available cues (Dieckmann \& Rieskamp, 2007). Experts often learn to recognize which cues are most relevant for making accurate inferences and which cues to ignore (Shanteau, 1992b). Thus, using more information-intensive strategies, such as WADD, may be adaptive for novices, who can explore the relevance of different information by combining all available cues (Shanteau, 1992b).

Our findings on cue use are compatible with evidence that experts may rely on one cue, whereas students may use multiple cues (Ettenson, Shanteau, \& Krogstad, 1987). Interestingly, the two expert groups differed in the specific cues they considered, and one expert group was more similar to the novices in this regard. Specifically, for burglars, security in the property (i.e., the absence of a burglar alarm system) was the most important cue for determining burglary, whereas for police officers and students, the most important cue was access to the property (i.e., doors and windows on the ground floor). Others have similarly shown that burglars considered target hardening via alarm systems to be important (e.g., Buck et al., 1993). Furthermore, Ham-Rowbottom et al. (1999) found that access to the property was important to police officers, and there was more concordance between police officers and residents, but less between these two groups and burglars. Finally, the finding that novices used several less relevant cues is consistent with past research on expertnovice differences (Shanteau, 1992b).

The differences we observed between burglars and police officers in cue use may have arisen from the fact that their different perspectives are also associated with different types of learning experiences (i.e., direct learning for the former vs. indirect learning via observation, interview, and education and training for the latter). 
Typically, through direct learning with more-or-less immediate feedback, burglars would have learned the best cues for selecting a property to be burgled. By contrast, police officers may be missing information about a property that was burgled or even have misinformation. They also only receive information about burglaries that are reported. Furthermore, typically they are not given immediate feedback about the outcomes of their predictions (i.e., investigations and charges). Such conditions make learning difficult (Bolger \& Wright, 1994), and so may lead to poor performance (Shanteau, 1992a). Residents (students, in this case) may share the views of police officers, because they may acquire their knowledge from police messages.

The present study is unique in its efforts to compare the ability of TTB and WADD in predicting behavior in the crime domain, to compare experts' and novices' strategies (as well as information use), and to compare the decision behavior of experts from different perspectives. Indeed, our findings extend the psychological literatures on decision making and expertise in several ways. First, these findings point to another condition under which heuristics may be preferred over WADD - namely, under expertise rather than novelty. They also suggest another environmental domain, residential burglary, in which heuristics may be effective in making accurate predictions (i.e., predicting burglars' choices), and therefore should be promoted. The present findings also highlight the importance, when expert-novice differences are studied, of going beyond the amount and type of information used to how that information is used. Finally, and in a related fashion, these findings indicate that quality, not just quantity, of information use should be considered when distinguishing between experts and novices. Future research could further examine all of these issues in other domains, as well as seek to explain the differences we observed among the three groups. We have provided some possible explanations that could be tested. Beyond this, future research could study expert-novice differences, using variants of TTB and WADD in order to better isolate the features of both strategies that are robust predictors of experts' and novices' choices.

From a practical standpoint, the present findings raise some concerns. First, there are concerns over the ability of the police to detect and investigate residential burglary, and to advise on its prevention. Second, there are concerns over the ability of citizens (in this case, students who have a high rate of burglary; see Nicholas, Kershaw, \& Walker, 2007) to effectively protect themselves against becoming victims of burglary. Fortunately, the fact that burglars may be using a heuristic implies that it may be easy for the police and citizens to adjust their thinking about burglary to concord with burglars'. This concordance is crucial, since residential burglary is a frequent crime. In the meantime, our findings underscore the problem that although police officers have learned to think like a criminal in terms of the decision strategy used, they have yet to know what the criminal is thinking in terms of the cues used.

\section{AUTHOR NOTE}

We thank Karen Souza for her assistance with the literature review of burglary and Bettina von Helversen for her useful comments. Correspondence concerning this article should be addressed to R. Garcia-Retamero, Facultad de Psicología, Universidad de Granada, Campus Universitario de Cartuja s/n, 18071 Granada, Spain (e-mail: rretamer@ugr.es).

\section{REFERENCES}

Bergert, F. B., \& Nosofsky, R. M. (2007). A response-time approach to comparing generalized ration and take-the-best models of decision making. Journal of Experimental Psychology: Learning, Memory, \& Cognition, 33, 107-129.

Bolger, F., \& Wright, G. (1994). Assessing the quality of expert judgement: Issues and analysis. Decision Support Systems, 11, 1-24.

BröDER, A., \& Gaissmaier, W. (2007). Sequential processing of cues in memory-based multiattribute decisions. Psychonomic Bulletin \& Review, 14, 895-900.

Buck, A. J., Hakim, S., \& Rengert, G. F. (1993). Burglar alarms and the choice behavior of burglars: A suburban phenomenon. Journal of Criminal Justice, 21, 497-507.

Czerlinski, J., Gigerenzer, G., \& Goldstein, D. G. (1999). How good are simple heuristics? In G. Gigerenzer, P. M. Todd, \& the ABC Research Group (Eds.), Simple heuristics that make us smart (pp. 97118). Oxford: Oxford University Press.

Dhami, M. K., \& Ayton, P. (2001). Bailing and jailing the fast and frugal way. Journal of Behavioral Decision Making, 14, 141-168.

DHAMI, M. K., \& HARRIES, C. (2001). Fast and frugal versus regression models of human judgment. Thinking \& Reasoning, 7, 5-27.

Dhami, M. K., Hertwig, R., \& Hoffrage, U. (2004). The role of representative design in an ecological approach to cognition. Psychological Bulletin, 130, 959-988.

Dieckmann, A., \& Rieskamp, J. (2007). The influence of information redundancy on probabilistic inference. Memory \& Cognition, 35, 1801-1813.

Ettenson, R., Shanteau, J., \& Krogstad, J. (1987). Expert judgment: Is more information better? Psychological Report, 60, 227-238.

Garcia-Retamero, R., Hoffrage, U., \& Dieckmann, A. (2007). When one cue is not enough: Combining fast and frugal heuristics with compound cue processing. Quarterly Journal of Experimental Psychology, 60, 1197-1215.

Garcia-Retamero, R., Takezawa, M., \& Gigerenzer, G. (2008). Group communication and decision-making strategies. Psicothema, 20, 753-759.

Garcia-Retamero, R., Wallin, A., \& Dieckmann, A. (2007). Does causal knowledge help us be faster and more frugal in our decisions? Memory \& Cognition, 35, 1399-1409.

GigerenZer, G. (2007). Gut feelings: The intelligence of the unconscious. New York: Viking.

Gigerenzer, G., \& Goldstein, D. G. (1996). Reasoning the fast and frugal way: Models of bounded rationality. Psychological Review, 103, 650-669.

Hammond, K. R. (2000). Judgments under stress. New York: Oxford University Press.

Ham-Rowbottom, K. A., Gifford, R., \& Shaw, K. T. (1999). Defensible space theory and the police: Assessing the vulnerability of residents to burglary. Journal of Environmental Psychology, 19, 117-129.

Johnson, E., \& PAYNe, J. (1986). The decision to commit a crime: An information processing analysis. In D. B. Cornish \& R. V. Clarke (Eds.), The reasoning criminal (pp. 170-185). New York: Springer.

Mata, R., Schooler, L. J., \& RiesKamp, J. (2007). The aging decision maker: Cognitive aging and the adaptive selection of decision strategies. Psychology \& Aging, 22, 796-810.

Nee, C., \& Meenaghan, A. (2006). Expert decision making in burglars British Journal of Criminology, 46, 935-949.

NeE, C., \& TAYLOR, M. (2000). Examining burglars' target selection: Interview, experiment, or ethnomethodology? Psychology, Crime, \& Law, 6, 45-59.

Nicholas, S., Kershaw, C., \& Walker, A. (2007). Crime in England and Wales 2006/07. London: Home Office.

Phelps, R. H., \& ShanteaU, J. (1978). Livestock judges: How much 
information can an expert use? Organizational Behavior \& Human Performance, 21, 209-219.

RiesKamp, J., \& HofFrage, U. (2008). Inferences under time pressure: How opportunity costs affect strategy selection. Acta Psychologica, 127, 258-276.

RieskAMP, J., \& OtTo, P. E. (2006). SSL: A theory of how people learn to select strategies. Journal of Experimental Psychology: General, 135, 207-236.

Shanteau, J. (1988). Psychological characteristics and strategies of expert decision makers. Acta Psychologica, 68, 203-215.

Shanteau, J. (1992a). Competence in experts: The role of task characteristics. Organizational Behavior \& Human Decision Processes, 53, 252-266.

Shanteau, J. (1992b). How much information does an expert use? Is it relevant? Acta Psychologica, 81, 75-86.

Shanteau, J., Grier, M., Johnson, J., \& Berner, E. (1991). Teaching decision-making skills to student nurses. In J. Baron \& R. V. Brown (Eds.), Teaching decision-making to adolescents (pp. 185-206). Hillsdale, NJ: Erlbaum.

SHAW, K. T., \& GIFFORD, R. (1994). Residents' and burglars' assessment of burglary risk from defensible space cues. Journal of Environmental Psychology, 14, 177-194.

Wright, R., Logie, R. H., \& Decker, S. H. (1995). Criminal expertise and offender decision making: An experimental study of the targetselection process in residential burglary. Journal of Research in Crime \& Delinquency, 32, 39-54.

\section{NOTES}

1. Cue rankings were used to break ties between cues when generating the predictions of TTB when cues had the same weight. This occurred in
$1.34 \%$ (police officers), $3.13 \%$ (students), and $5.45 \%$ (burglars) of cases. Alternatively, breaking ties randomly did not affect our conclusions.

2. Evaluating the two strategies on the basis of this fit measure is appropriate, because the two strategies make unambiguous predictions in all trials, and they have no free parameters fitted to the data. This means that their flexibility in prediction is identical.

3. For example, imagine that the cue values for Properties A and B are 10000000 and 01111111 , respectively, where 1 represents the presence of a cue value, and cues are arranged from left to right in decreasing order of weight. Here, TTB would predict the choice of Property A, because the first ranked cue discriminates between the two properties and the property with the cue value present (i.e., A) is chosen. By contrast, WADD would predict the choice of Property B, because it has more cue values, and so has the greater sum. This trial therefore discriminates between TTB and WADD, and participants using one of the two strategies would make opposite choices to those who employed the other strategy.

4. Because subjective cue weights were used to generate the strategies' predictions, the proportion of discriminating trials varied slightly across participants. The average percentage of discriminating trials was $22.88 \%$ $(S D=2.23), 21.31 \%(S D=1.95)$, and $21.44 \%(S D=2.18)$ for police officers, burglars, and students, respectively.

5. Computing the correlation on the basis of the strategy fit over the discriminating trials means that the correlation for WADD would be the same size as that for TTB, but in the reverse direction.

(Manuscript received April 22, 2008; revision accepted for publication September 2, 2008.) 